\title{
Mnemonic Effectiveness of CL-motivated Picture-elucidation Tasks in Foreign Learners' Acquisition of English Phrasal Verbs*
}

\author{
Hussein Muhammadi Farsani \\ Department of English, Faculty of Foreign Languages, University of Isfahan, Iran \\ Email: hmfarsani@gmail.com \\ Ahmad Moinzadeh \\ Department of English, Faculty of Foreign Languages, University of Isfahan, Iran \\ Email: moin@fgn.ui.ac.ir \\ Mansoor Tavakoli \\ Department of English, Faculty of Foreign Languages, University of Isfahan, Iran \\ Email: tavakoli@fgn.ui.ac.ir
}

\begin{abstract}
Learning the behavior/meaning of English phrasal verbs can prove challenging to the foreign language learner. This is mainly because such verbs, in their combinations with various prepositional/adverbial particles, often exhibit figurative senses not readily transparent to the learner. The absence of a culturally/socially rich experiential language setting giving rise to image-schematic patterns, as conceived in Cognitive Linguistic theory, might be an inhibiting factor in this regard. The present study takes this issue as its point of departure and examines whether pedagogical, picture-cued tasks revealing imageschematic concepts behind phrasal verbs would facilitate learners' inferences from their concrete to more abstract senses. It also aims to find out if such tasks would help enhance participants' acquisition and use of such verbs in the long run. For this purpose, 56 intermediate-level students aged 12-18 were randomly selected to go through the process of learning 42 phrasal verbs in an experimental or a control group each comprising 28 learners. Comparison of the results from the tests reveal a positive effect for picture-elucidation tasks - in contrast to more traditional use of discrete dictionary definitions - raising learners' awareness toward imageschematic concepts behind English phrasal verbs. The study also carries implications for foreign language pedagogy as the tasks designed for the purposes of this study could be effectively used and further explored within the framework of Task-Based Language Teaching.
\end{abstract}

Index Terms-Cognitive Linguistics (CL), image schemas, image-schematic picture-cued tasks, English phrasal verbs (EPVs), task-based language teaching (TBLT)

\section{INTRODUCTION}

English Phrasal verbs (henceforth EPVs) constitute a class of verbs that provides particular difficulty for the foreign language learner (Condon, 2002; Rudzka-Ostyn, 2003) as they are made up of a main verb element and a prepositional/adverbial particle which more often than not extends the literal meaning of the verb into figurative significance (Dirven, 2001). Such configurations and the senses they embody create less of an obstacle for native speakers as they come across abundant evidence of their use from an early age (Mandler, 2004; Tomasello, 2003). This early, gradually expanding experience undoubtedly aids the native speaker in forming the necessary "image schemas" whose properties would then scaffold the construction of abstract concepts signifying in turn relevant linguistic expressions which embody abstraction in meaning (see Geeraerts \& Cuyckens 2007 for various articles; see also Lakoff \& Johnson 1980, 1999). Such image schemas, in the words of Johnson (1987), "emerge as meaningful structures for us chiefly at the level of our bodily movements through space, our manipulations of objects, and our perceptual interactions" (p. 29). In this sense, an image schema is the product of human perceptual interaction with real-world events and processes, "a recurrent pattern, shape, or regularity in, or of, our actions, perceptions, and conceptions" (Rohrer 2007, p. 35). In fact, image schemas act as "buffer" between bodily percepts and more abstract conceptual domains, mapping real world structure onto conceptual structure (Fauconnier \& Turner, 2002). Cognitive linguists have invariably stressed and successfully demonstrated the fundamental role image schemas play in the construction and

\footnotetext{
* The authors would like to thank anonymous TPLS reviewers for their invaluable comments on an earlier draft of this article. All shortcomings remain solely ours.
} 
interpretation of linguistic expressions at various levels of abstraction (see, for example, Lakoff, 1987; Lakoff \& Johnson, 1980 among others).

A number of CL-oriented research studies have aptly demonstrated that native speakers are subconsciously aware of such image schemas and constantly manipulate them in their application and comprehension of figurative language (see, for example, Gibbs, Bogdonovich, Sykes \& Barr, 1997; Gibbs \& O’Brian, 1990; Gibbs, Strom \& Spivey-Knowlton, 1997; Nayak \& Gibbs, 1990). The researchers believe these image schematic patterns are indispensible to appropriate understanding and use of figurative language.

For non-native learners of English in a foreign language setting, as postulated in the present research study, phrasal verbs seem a strange and elusive part of language to understand and use (Condon, 2008; Side, 1990). This is mainly because these learners are somehow removed from and are largely unfamiliar with the experience-embedded imageschematic concepts responsible for the formation of such linguistic expressions and their various senses (Tyler \& Evans, 2005). This unfamiliarity is itself due to the fact that learners in a foreign language context do not share the lifelong socio-cultural experiences of the native speaker so as to arrive at the metaphoric extension a certain phrasal verb might encompass (see Ellis \& Laporte, 1997; Tyler \& Evans, 2001). Moreover, metaphor is a property of the human conceptual organization arising as a result of interaction within a certain environmental and socio-cultural context rather than a characteristic specific to linguistic elements per se, the received view from formal linguistics (Lakoff \& Johnson, 1980, 1999; McGlone, 1996). As such, to grasp the metaphoric senses of linguistic expressions, the learner should have gone through the life-long experiential process that gave rise to this metaphoric extension in the first place $^{1}$, the process Lakoff (1987) and Johnson (1987) refer to as "conceptual projection" (for a detailed description and analyses of the conceptual projection process, see Johnson, 1987 and Lakoff, 1987). This is apparently impossible in the case of the foreign language learner who inhabits a different linguistic/cultural environment, and would eventually result in learners' total avoidance or erroneous understanding and application of this class of verbs (Dagut \& Laufer, 1985; Ellis \& Lapporte, 1997).

Undoubtedly, learning to recognize, comprehend, and actively use phrasal verbs is an inevitable part of learning English as a second/foreign language. The publication of numerous textbooks and reference dictionaries focusing exclusively upon the teaching and learning of phrasal verbs bears testimony to the prominence of this claim (among numerous textbook publications, see Allsop, 1990; Hart, 2009; McCarthy \& O'Dell, 2007; for dictionaries and other reference works, see Cambridge Phrasal Verbs Dictionary, 2006; Longman Phrasal Verbs Dictionary, 2000; Oxford Phrasal Verbs Dictionary for Learners of English (McIntosh, 2006)). Phrasal verbs are frequently used in spoken English, especially in informal, conversational exchanges as well as in fiction and film (Burke, 2002). Learners encounter them in diverse contexts of use and need to find out about their meaning if they intend to communicate efficiently (Dagut \& Laufer, 1985; Rudzka-Ostyn, 2003). Misunderstanding and embarrassment often arise as a result of learners' avoidance and misuse of even a single phrasal verb (take, as an illustration, learners' frequent confusion over instances of prepositional/adverbial combinations with "look" as in look for, look into, look up, look forward, look at, look out, look up to, look down on, look after, and so on). The main challenge, as Azzaro (1988) points out, seems to originate from the widespread misconception among learners - as envisaged by teachers and textbooks - that verbparticle combinations do not follow precise patterns of construction and are to be merely memorized.

Even traditional EFL textbooks encourage learners toward the misleading conception that phrasal verbs and their verb-particle arrangements are absolutely random and need to be memorized rather than analyzed. As an illustration, Richards et al. (2005, p. 60) presents learners with a list of unrelated English phrasal verbs where the learner is supposed to pair a phrasal verb and its definition in a matching task. Undeniably, the sentences are so designed as to provide learners with helpful clues to the meaning of the phrasal verb in sentence context. Nonetheless, although the authors make generous use of pictures, cartoons, photos, and drawings elsewhere throughout the book, they have made no attempt to encourage the learner to grasp conceptual aspects of phrasal verbs through similar pictorial elucidations or informative illustrations of any sort. In fact, they seem to have considered the use of illustrations unnecessary and futile with respect to phrasal verbs and this is the issue this research study is perhaps most concerned with.

In order to enhance learners' recognition of abstract meaning conceptualization in phraseology, various researchers have specifically used CL theory and have devised pedagogical strategies to help learners cope with difficulties in this regard (see Boers, 2000; Condon, 2008, 2002; Csábi, 2004; Kurtyka, 2001; Rudzka-Ostyn, 2003; Side, 1990 among others). Although many such approaches have yielded fairly positive results in terms of their instructional objectives, it seems that the majority have, nevertheless, attempted to provide tables or representations depicting abstract relations between and among particles responsible for making up different phrasal verb constructions. Such abstract depictions and analyses needlessly - and perhaps inadvertently - make the task of acquiring nuances in meaning even more complicated and gruesome for the language learner. In essence, according to Bolinger (1971), if one intends to change learners' views that phrasal verbs are arbitrary and random combinations of verb-particle associations, clear and

\footnotetext{
${ }^{1}$ Recent approaches in foreign language pedagogy, from the more general Communicative Language Teaching Approach to specific methods like Task-Based Instruction, have all been concerned with producing a naturalistic environment of teaching/learning in foreign language contexts. All efforts have been directed toward the creation of process-oriented, real-life "tasks" that simulate an authentic environment similar to that of a native speaker (for more information, see Nunan, 1999; Richards \& Rogers, 2001).
} 
comprehensible conceptual delineations are inevitably required in any learning/ teaching context (see also Boers, 2000 in this regard).

Building upon CL theory, the present study takes a novel perspective toward the teaching of phrasal verbs in a foreign language context. The basic idea here is that if learners are to properly acquire and use phrasal verbs in English, the instruction of the abstract senses of their prepositional/adverbial particles is as futile as vague dictionary definition s stating the meaning of such terms ${ }^{2}$. Although dictionary compilers and editors have chosen good examples and have provided clear definitions, most students would still become completely baffled over the use of the same phrasal verb in a more figurative sense as in the sentence "Hold on to hope" (see part A \& C of the Appendix for an imagistic representation of this metaphoric sense). In practice, many teachers have to resort to translation which may sometimes complicate matters to a great extent (see Vahid Dastjerdi \& Talebinezhad, 2002 for a discussion of Persian university students' problems with figurative language use).

Picture-elucidation tasks in this study seek to integrate creativity and authenticity into the teaching of a number of phrasal verbs in English. These tasks are specifically designed to guide learners through various levels of abstraction in 42 instances of English phrasal verbs, building upon more concrete senses leading the learner smoothly toward having a better, fully operational grasp of their abstract senses. Tasks, within Task-Based Language Teaching (TBLT), are defined as learning activities whose main purpose is to help focus learners' attention and raise their awareness of a specific aspect of language (Willis \& Willis, 2007). As Long (1985) puts it, "...by task is meant the hundred and one things people do in everyday life, at work, at play, and in-between" (p. 89). As such, tasks draw on and reflect the experiential and humanistic aspects of learning (Nunan, 1999; Samuda \& Bygate, 2008). A "picture-elucidation task," in particular, is one type of cognitive awareness-raising task (Skehan, 1998) in which learners' attention is directed toward salient features of one or a series of pictorial sketches, cartoons or photos rendering a more concrete aspect of the meaning of a linguistic expression. This concrete aspect then gradually leads learners to recognize similar salient features in more abstract pictorial elucidations of the linguistic expression in question. "Discovery" plays a vital part here in directing learners toward then intended goals of the task (for discovery tasks see Breen, 1987; Littlewood, 2004). Various learners' books (Collis \& Kohl 1999; Collis, 2007) have utilized picture-cued elements to stimulate learner recognition and retention of various figurative items in English albeit in informal, non-professional terms.

With respect to the unique CL-informed perspective adopted in our treatment of EPVs, the research questions addressed in this study are as follows:

1. Does a CL-motivated instructional approach help EFL learners better acquire EPVs, compared to traditional strategies such as the use of dictionary definitions and/or the provision of plain statements of meaning?

2. Do pictorial elucidations evoking basic image-schematic concepts behind phrasal verbs significantly enhance participants in their understanding, retention, and proper use of EPVs?

3. Does a pictorial representation of a more concrete sense of a certain EPV assist participants' recognition of a more figurative sense of that EPV?

\section{METHOD}

\section{A. Participants}

The participants initially selected to take part in this study were 62 young male learners (aged 12-18), from a total population of approximately $500 \mathrm{EFL}$ students, placed at intermediate levels of English proficiency at a private language school in Isfahan, Iran. In order to ensure homogeneity among the participants in the experiment, the placement procedure was carried out using a version of the Oxford Placement Test (OUP, 2005). All the students in the study shared Persian as their mother tongue. Prior to entering their relevant courses of instruction, participants were informed that they were going to receive instruction concerning a number of EPVs incorporated into their regular summer English courses at the institute.

In order to ascertain homogeneity with respect to knowledge of EPVs, a pretest comprising items testing potential participants on random instances of such verbs was also run. Eventually, six students with extreme scores on the pretest were eliminated from the total number of potential participants (for more information regarding the pretest results, see the section on Results further below). Thus, in the final stage, a total of 56 participants were randomly assigned to two groups in this study using tables of random numbers:

1. An "experimental group," arranged to receive treatment in the form of tasks including picture elucidations of the EPVs used in this study.

2. A "control group," which was to receive instruction on the same EPVs as in the experimental group. However, this was carried out through the presentation of dictionary definitions and/or example sentences containing uses of the verbs in question (see the section on Instruction and Procedures below for a discussion of materials and classroom procedures).

Table I below displays the results of an analysis of the scores gained by the selected 56 participants on the OPT:

\footnotetext{
${ }^{2}$ As an example of a dictionary definition of "hold on to," see the following from Longman dictionary of Contemporary English (2009, p. 837): [1] to have your hands/arms tightly around something: Hold on to my arm. [2] keep something rather than losing it, selling it, or giving it to someone else: $I$ think I'll hold on to these old records for now.
} 
TABLE I

MEAN SCORES DETERMINING HOMOGENEITY BETWEEN GROUPS ON THE OPT

\begin{tabular}{|l|l|l|l|}
\hline Groups & Mean & Number & Std. Deviation \\
\hline Experimental & 34.82 & 28 & 2.72 \\
\hline Control & 35.92 & 28 & 2.96 \\
\hline Total & 35.37 & 56 & 2.87 \\
\hline$p$-value & $\mathrm{p}>.8$ & \multicolumn{3}{|l}{} \\
\cline { 1 - 2 }
\end{tabular}

To control for the teacher variable, the main researcher in the study was given the responsibility to teach both groups so that any differences between groups in their results could be ascribed to the given treatment rather than personal styles of instruction. However, all three researchers collaborated in monitoring classroom activity and interaction and checked the materials and tests implemented.

\section{B. Materials}

After ensuring homogeneity in their general English proficiency levels (see Table I above) and prior to being assigned to any groups, the potential participants were required to take a written pretest containing a total of 84 gapfilling items in 2 sections each comprising 2 cloze-type passages. This division into 2 sections was for practical reasons, since testing a relatively large number of phrasal verbs in a single cloze task would prove both impossible to design and confusing for the students to respond to $^{3}$. Moreover, a cloze task was preferred over isolated, decontextualized sentences as these would offer students no meaningful clues as to the selection of the appropriate EPVs for a certain context of use. Translations in the pretest, as in all other tests used in the study, were generally avoided ${ }^{4}$.

The first half of the pretest - the "concrete section" - used two cloze passages to examine potential participants knowledge of 42 phrasal verbs in their more tangible senses. The second - "figurative" - section, on the other hand, verified learners' awareness of more metaphorical meanings of the same 42 items included in the first section of the test. As such, the concrete/abstract senses of the phrasal verbs in question were tested separately.

No specific criteria were applied in choosing the 42 phrasal verbs examined in the pretest; we only made sure each selected phrasal verb could be paired based on a more concrete and a more figurative aspect of its meaning.

The pre-, post-, and delayed post-tests were all similar in design in that they all comprised parallel tasks (cloze gapfill procedures dividing concrete/figurative phrasal verb senses); nonetheless, there were differences incorporated to minimize damage to the reliability of the scores we obtained from each test. One important difference between the pretest and the other tests was the inclusion of multiple-choice items (MCIs) each corresponding to a gap in the cloze task $^{5}$.

An immediate and a delayed posttest were also given to examine participants concerning their recognition and use of EPVs after passing their relevant courses of instruction. The immediate posttest was designed to verify participants' performances immediately after receiving their relevant treatments in each group, whereas the purpose of the delayed posttest was only to check for retention of similar material about four weeks following instructional procedures.

The two posttests were similar in design to the pretest; nevertheless, distinctions were incorporated as to improve test reliability factors. Firstly, the texts in each test differed in their subject matter, content, and wording to prevent repetition. Further, we only presented the participants with a jumbled list of the phrasal verbs at the beginning of each cloze passage in the posttests as to compel learners to "think over" and choose items to match gaps in the cloze tasks. The arrangement and use of phrasal verb instances in the four passages was varied as well.

With regard to scoring procedures, a correct answer (that is, the appropriate choice of one phrasal verb to complete a single gap in each passage) on each of the tests would count as "one score" and each incorrect/no response would otherwise count as "zero." Therefore, a total of 84 would be a complete score a participant could gain on every single test, and a total of 42 on each concrete/abstract section of the tests. Participants' informal oral/written classroom descriptions and reports were not included in the scoring, though.

The pictures, drawings, and photos used in classroom tasks were selected from various sources. Some were conveniently taken from the World Wide Web, while others were drawn by a cartoonist we consulted. One important feature we had in mind while choosing pictures or having them sketched was that the pictures had to conspicuously display the intended meaning figured in a certain EPV. For instance, if a schematic image of "hold on" were to be displayed, we made sure the picture chosen contained features that would readily provoke a mental image of "hold on" in the mind of the user (see, e.g., part $\mathrm{C}$ of the appendix). Further, we made sure the paired concrete abstract pictures displayed shared characteristics that were easily discoverable on the part of the learner (see appendix, part A).

\section{Instruction and Procedures}

\footnotetext{
${ }^{3}$ Language testing principles instruct test designers to include an average of 25-30 gaps in a cloze task consisting of a standard of 220-250 words (see Brown, 2010; Hughes, 1989; Madsen, 1983).

${ }^{4}$ In some instances, however, we were obliged to include translations of test rubrics or even had to translate difficult vocabulary within the text to prevent misunderstanding of general sentence meaning on the part of test takers.

${ }_{5}^{5}$ This was simply because, here, we only checked learner's "recognition" of a limited number (each MCI presented five choices for a single corresponding gap) of phrasal verbs for each cloze test gap, and not their productive, independent use (Brown, 2010 considers 3 to 7 choices for each MCI as optimal).
} 
Before administering the pretest, participants were briefed about EPVs (giving examples they had already been practically familiar with, such as get up, go out, and come back) and were assured that their scores on the experimental tests would have no negative effect upon their end-of-term results.

The instruction of phrasal verbs was integrated into an extended general EFL program lasting over 3 consecutive summer months in 3 one-and-a-half-hour sessions per week (a total of 42 sessions). Furthermore, each session was divided into two 40-minute halves with a ten-minute break in between. Owing to the bulk of content students had to cover in standard courses, and for practical teaching considerations, we chose to introduce one phrasal verb every session, including both the more concrete and the more abstract senses. Both the experimental and the control group received the same phrasal verbs in their courses of instruction. The basic rationale for the inclusion of only one phrasal verb was that a single phrasal verb had to be examined in several contexts of formal/informal, concrete/abstract use. Further, in subsequent sessions, we began to include review activities of the phrasal verbs students had been taught in earlier sessions. After all, our delayed post-test aiming at retention of phrasal verbs would not exhibit any validity if we did not include elements of retention throughout our course of instruction.

The criteria for choosing which phrasal verbs to include were variation in base verb (be, come, go, hold, take) and variation in accompanying particles (in, on, up, down, out, and back). We consulted and randomly chose EPVs from classifications provided by Rudzka-Ostyn (2003) and from among the instances cited in Allsop (1990). The classifications were not, however, criterial in our choices of EPVs. Rather, the basic idea was to select items with a variety of particle and/or base verb combinations. This was because, unlike some previous studies (Condon, 2008; Dagut \& Laufer, 1985), we did not intend to instruct the different senses and foci of a specified group of "particles" accompanying a verb base in relation to those particles' abstract representations. As mentioned before, for purposes of this research study, we separated the more concrete and the more abstract senses of each phrasal verb taught.

The instruction and practice procedures "experimental group participants" went through essentially included pictures, photos, images, and drawings that were representative of the image-schematic concepts giving rise to a certain phrasal verb meaning. To begin, students were randomly divided into groups of two or three. Copies of the initial picture and its accompanying sentences containing a concrete use of an EPV were given to every group. They were told to read the sentences carefully, look at the picture drawing, and try to recognize the meaning of the phrasal verb in context. The teacher also pointed out the fact that the picture represented an image which encompassed the meaning they were looking for.

After correctly identifying the meaning of the verb, the learners were given time to think over and discuss their "explanations" of salient picture features before they presented their oral/written, first/second language explanations to the teacher and other groups in class (for sample experimental participant descriptions, see part B in the Appendix). The purpose for this presentation by students was two-fold: to determine if they had worked out the appropriate meaning of the phrasal verb in focus and to correct any possible misconceptions about the intended features shown in the pictures.

In the second half of the session, the teacher started by handing out a different picture with a different set of sentence samples embodying a second more figurative sense of the EPV under analysis ${ }^{6}$. The same procedure as before was carried out here; but participants were made aware that they could draw on their understanding of the initial picture task and the more concrete usage of the verb to arrive at the more figurative sense. The purpose here was to ease learners into making a transition to the more abstract meaning of the phrasal verb they were working on. To conclude, the teacher further helped clarify commonalities between the pictures and, as such, intimate relations between phrasal verb meanings. The idea here was that "discovering" common attributes between the paired concrete and abstract image patterns would strengthen learners' association and retention of the more remotely evident sense(s) of an EPV.

The same sequence of phrasal verb instruction was carried out for the "control group participants". However, the teacher avoided using any visual stimuli to help learners work out the concrete/abstract meaning of a phrasal verb; instead, in the first half of the lesson, after being assigned to groups of two/three, the participants were given a phrasal verb in the form of a regular matching, sentence completion, or multiple-choice task of a more concrete sense and were given the chance to look up its meaning in a dictionary. Unlike their peers in the experimental group, control group participants were not supposed to provide any explanations regarding the meaning of the EPV taught.

As the class convened for the second half of the lesson, participants were given an exercise (once again in the form of a typical matching, multiple-choice and/or completion task) containing a more abstract use of the same phrasal verb introduced earlier in the first part of the session. They were instructed to complete the exercises by inferring the figurative meaning of the same phrasal verb the more concrete definition of which they had already identified. The instructor also helped, through translations or paraphrases, if learners ran into problems with overall sentence meaning. Table II below shows the sequence of activities used in the classroom for both groups in the study:

\footnotetext{
${ }^{6}$ Note that at times, to smooth this "transition" to the more abstract meaning, a series of consecutive pictures were utilized (see part C of the Appendix for one example in this regard; see also Spivey-Knowlton et al., 1998).
} 
TABLE II.

SEQUENCE OF CLASSROOM ACTIVITIES FOR THE CONTROL \& EXPERIMENTAL GROUPS

\begin{tabular}{|c|c|c|}
\hline Study Groups & Class Time: First Half & Class Time: Second Half \\
\hline Control Group & Introduction \& Interactive Practice: & Introduction \& Interactive Practic \\
\hline $\begin{array}{l}\text { Experimental } \\
\text { Group }\end{array}$ & $\begin{array}{l}\text { Examples of More Concrete Phrasal } \\
\text { Verb (e.g. hold on to the door) }\end{array}$ & $\begin{array}{l}\text { Abstract Instances of Phrasal Verb (e.g. hold } \\
\text { on to hope) }\end{array}$ \\
\hline
\end{tabular}

In order to assess group achievement with regard to their methods of instruction, an immediate posttest was administered to both groups as soon as their courses of instruction were over (for test facets, see Materials above). Approximately four weeks later, a delayed posttest was administered to all the participants ${ }^{7}$.

\section{RESULTS}

For the analysis of the numerical data from our tests, the SPSS software was used. The results we obtained from our data analyses, in terms of mean score differences and their corresponding $p$-values, were divided into three categories:

1. The mean scores obtained for each of the two groups in the study with separate analyses of average performance in each section of the pre-, post-, and delayed post-tests;

2. The amount of learning that took place as a result of the treatment from the pretest to the immediate posttest calculated by comparing the relevant group mean scores;

3. The degree of learning from the pretest to the delayed posttest plus the extent to which the participants in each group recalled the material they had learned verified through comparing the means from the immediate to the delayed posttest.

In order to compare the results from the control and experimental groups, the average scores for their respective performances on all the three tests in the study were analyzed immediately after obtaining the data. Table III depicts the overall average scores and their $p$-values for both groups on the three tests administered in the study:

TABLE III.

OVERALL MEAN SCORES ON THE PRE-, IMMEDIATE POST-, AND DELAYED POST-TESTS

\begin{tabular}{|l|l|l|l|}
\hline Study Groups & Pre-Test & Immediate Post-Test & Delayed Post-Test \\
\hline Control Group & 3.18 & 40.07 & 26.93 \\
\hline Experimental Group & 3.14 & 53.86 & 41.93 \\
\hline Significance & $\mathrm{p}>.8$ & $\mathrm{p}<.005$ & $\mathrm{p}<.005$ \\
\hline
\end{tabular}

Table III demonstrates an advantage for the experimental group on both the immediate and the delayed posttests. In keeping with the teaching practices in our group instructions (see Table II further above) as well as maintaining more precision in the results gained, an attempt was made to have two sections on each of the tests: a primary section checking the comprehension/use of more concrete instances of the EPVs taught, and a secondary section checking for the learning and appropriate use of the corresponding figurative senses of the same EPV. This allowed us the further benefit of providing more detailed analyses of experimental and control group performances on various subsections of each test. Table IV displays these detailed measurements and their relative $p$-values for both groups in the study:

TABLE IV.

DETAILED MEAN SCORES ON EACH SECTION OF THE PRE-, IMMEDIATE POST-, AND DELAYED POST-TESTS

\begin{tabular}{|l|l|l|l|l|l|l|}
\hline \multirow{2}{*}{ Study Groups } & Pre-Test & \multicolumn{2}{|l|}{ Immediate Post-Test } & \multicolumn{2}{|l|}{ Delayed Post-Test } \\
\cline { 2 - 7 } & Part $(A)$ & Part $(B)$ & Part $(A)$ & Part $(B)$ & Part $(A)$ & Part $(B)$ \\
\hline Control Group & 1.89 & 1.29 & 26.76 & 12.96 & 19.82 & 7.11 \\
\hline $\begin{array}{l}\text { Experimental } \\
\text { Group }\end{array}$ & 1.93 & 1.21 & 30.14 & 23.71 & 26.25 & 15.75 \\
\hline Significance & $\mathrm{p}>.8$ & $\mathrm{p}>.7$ & $\mathrm{p}=.051$ & $\mathrm{p}<.005$ & $\mathrm{p}<.005$ & $\mathrm{p}<.005$ \\
\hline
\end{tabular}

The means obtained on the "more concrete" section (Part A) of the immediate posttest reveals insignificant difference in performance between the control and the experimental groups. In contrast, the mean scores for the "more abstract" section (Part B) of the same test illustrate highly significant results for the experimental group as opposed to the unsatisfactory average for the control group. Both groups did have a drop in their mean scores on the first part of the delayed posttest, with the experimental group performance still significantly better. However, although the two groups gained much lower results on the second part of the same test with respect to their scores for the same section on the immediate posttest, the results indicate a significantly poor gain for the control group, only slightly more than half of the average on the second section of the immediate posttest.

Table $\mathrm{V}$ below illustrates the amount of learning that took place from the pre- to the immediate post-test as measured by subtracting participants' pretest scores from their respective scores on the immediate posttest. Although the table confirms greater benefit (almost double) from the CL-motivated approach for the more abstract section (Part 2), it only indicates slightly more gain (however insignificant) for the more concrete section (Part 1) by that group.

\footnotetext{
${ }^{7}$ There was no chance of delaying this test further since the students had to begin their next quarter a month from the end of our course and, thus, exposure to English would have probably confounded the results.
} 
TABLE V.

\begin{tabular}{|c|c|c|}
\hline \multirow[t]{2}{*}{ Study Groups } & \multicolumn{2}{|c|}{$\begin{array}{l}\text { Mean Differences between Pre- \& } \\
\text { Immediate Post-Tests }\end{array}$} \\
\hline & Part (1) & Part (2) \\
\hline Control Group & 24.86 & 11.68 \\
\hline Experimental Group & 28.21 & 22.50 \\
\hline Significance & $\mathrm{p}>.1$ & $\mathrm{p}<.005$ \\
\hline
\end{tabular}

The pattern appears quite different, however, when comparing the groups' respective average scores from the pretest to the delayed posttest, as displayed below in Table VI:

TABLE VI.

BETWEEN-GROUP MEAN DIFFERENCES BETWEEN PRE-TEST \& DELAYED POST-TESTS

\begin{tabular}{|l|l|l|}
\hline \multirow{2}{*}{ Study Groups } & \multicolumn{2}{|l|}{$\begin{array}{l}\text { Mean Differences between Pre- \& Delayed } \\
\text { Post-Tests }\end{array}$} \\
\cline { 2 - 3 } & Part (1) & Part (2) \\
\hline Control Group & 17.93 & 5.84 \\
\hline Experimental Group & 24.32 & 14.54 \\
\hline Significance & $\mathrm{p}<.005$ & $\mathrm{p}<.005$ \\
\hline
\end{tabular}

Here, the experimental group participants outperform their control group peers in both sections of the test (although both groups have significant drops in gain from their results on the immediate posttest). This is while the control group's performance decreases to a low mean on the second, "more abstract" part of the test in comparison to that of the experimental group. There is also a significantly greater reduction in average score on Part 2 for the control group compared to their score on Part 1 of the test.

\section{DISCUSSION}

\section{A. Response to Research Question One}

The results from this study lend strong support to the basic hypothesis that a CL-inspired approach to the instruction of EPVs enhances EFL learners' acquisition of these verbs. Analysis and comparison of group performance in various parts of the tests (see the Results section above) demonstrates significant results for experimental group participants who received phrasal verb instruction using CL-inspired picture-elucidation tasks. These conclusions are already in line with current research illustrating the merits of applying insights from wide-ranging CL-directed research to problems of foreign language pedagogy. In a thorough review of studies of CL theory applications to practical language pedagogy, Boers (2011) argues for the favorable evidence which demonstrates the effectiveness of CL-informed second language pedagogy in general. De Knop et al. (2010) also presents positive evidence from CL-motivated classroom research and emphasizes the need for a pedagogical approach that explicitly demonstrates the semantic and conceptual regularities exhibited in the language being taught. Such a perspective, they argue, would help produce, in the long run, maximal benefit in terms of classroom investment of time and resources. Norris and Ortega (2000) investigated the effectiveness of implicit and explicit L2 instruction and maintained a strong case for the latter believing that explicit instruction drawing on research synthesis and qualitative meta-analysis proves more efficient and long-lasting in terms of its effect on L2 learning.

The researchers in this study contend that a CL perspective, such as the one adopted here, can serve second/foreign language teachers by providing models and suggestions for the design of innovative tasks that provide related concrete visual stimuli in inferring abstract meaning. In fact, an important dimension of our research concerns drawing on "shared" concepts from both CL and TBLT, namely experientialism and awareness-raising, to devise novel tasks that effectively address learners' problems in foreign contexts of learning. In their review of feedback from CL research for task-based instruction, Robinson \& Ellis (2008) maintain that insights offered by CL can be fruitfully used in designing, sequencing, and creating tasks drawing on CL notions such as experientialization and conceptualization to maximize opportunities for learners in their analysis, interpretation, and use of various aspects of language. As Csábi (2004) also claims, offering challenge and motivation in second language teaching/learning options is a favorable aspect of CL theory and research yet to be discovered and usefully applied.

It is now generally agreed, following Paivio's dual coding hypothesis (Paivio, 1986), that a teaching/learning methodology drawing on channels other than purely linguistic ones such as drawings, visual representations, gestures, and the like can facilitate and improve not only the acquisition of a foreign language but also the retention of meaning and form through mental imagery and representation of verbal information. This study is one attempt at illustrating the practical merits of this hypothesis with a novel empirical procedure which is very promising (see also Skehan, 1998).

\section{B. Response to Research Question Two}

A quick look at the test results gained by our experimental group participants reveals that work on picture-cued tasks greatly improved their comprehension and proper use of EPVs. It seems that the enhanced recognition of concrete/abstract meanings in EPVs has been the result of participants' establishment of meaningful connections 
between concrete/abstract image-schematic visual stimuli presented to them. Paivio's dual coding theory is especially relevant here (see Paivio, 1986) as visual representation of information contained in a linguistic expression seems to positively scaffold and enhance mental imagery, as the results of this study demonstrate.

Another important aspect of this enhancement is related to what Talmy (2008) refers to as the fundamental attentional system of language. He maintains that learners attend to the interactive salient features shared by the linguistic expression, the conceptual content, and the context at hand to create meaning. It is the integration of related sets of features presented by information from these various channels, rather than the pure linguistic expression, that helps discover meaningfulness in language (see also Rosch, 1977). What we have done in this study is the simple provision of the conceptual content and the context at hand accompanying the presentation of a phrasal verb that has "elucidated," in the words of Boers et al. (2008), learners' entry into various levels of meaning of an EPV. Learners' understanding of the semantics of an EPV is the result of their deriving vital information represented in physical-spatial, image-schematic patterns "mimicked" in simple yet creatively-designed picture-elucidation tasks.

An encouraging dimension of the experimental group performance is their relative success in the effective retention of meaning of EPVs, compared to the significantly low outcome achieved by the control group. It is evident that both groups have been subjected to memory loss over the one-month time lapse between the immediate and the delayed posttest which is a natural part of any short-term course of language instruction (for detailed discussions of second/foreign language attrition, see De Bot, 1995; Schmid, 2006). However, the large gap between the results of the two groups on the retention test of more abstract EPV senses, with the experimental group gaining a mean twice as much as that for the control group, supports the mnemonic effectiveness of pictorial elucidations over a longer period of time when virtually no treatment with regard to phrasal verbs took place ${ }^{8}$. This is already in agreement with findings from other studies of mnemonic variables in pictorial elucidations motivated through a CL approach (Boers et al., 2008; Boers \& Lindstromberg, 2008). Boers et al. (2008), for example, examined ways in which pictorial elucidations of concrete linguistic expressions aided learners' recall of their more figurative usage. Similar to the results in this study, they found that pictorial representations of concrete/abstract meanings were highly beneficial to learners who tended to think in pictures; their data also demonstrated, perhaps surprisingly, that such representations further encouraged learners with a tendency to think in words to opt for visual imagery that seemed more motivating and helpful in nature.

Interestingly enough, contrary to the findings by Boers et al. (2008) above, an informal review of the test responses provided by our experimental participants revealed that the picture-cued tasks facilitated learners' retention of meaning, as well as their retention of "form." Perhaps, the reason for this success in remembering form, especially recall of which prepositional/adverbial article to use even in the case of abstract EPVs, could be attributed to the unique nature of pictorial tasks created and used in this study (see parts A \& C of the Appendix for representative samples). In fact, in our picture drawings, one salient feature particularly addressed was how the prepositional/adverbial particle was to be visually transparent.

Naturally, to direct participants' attention to minute distinctive features of "particles" in the picture tasks, teacher guidance and supervision was indispensible. Along with studies that encourage teacher intervention (see, for instance, Tyler \& Evans, 2005; Boers, 2011; Vahid Dastjerdi and Talebinezhad, 2002), we believe that teachers can play an extremely useful role in directing and maintaining learners' attention to such escapable but important aspects of pictorial representations of EPVs.

\section{Response to Research Question Three}

Perhaps, the most fundamental objective of the present study was to observe whether a visual representation of concrete meaning could guide learners' inferences of related abstract significance. Comparison of the results between the first and second sections of our posttests lends support to this notion in particular. In fact, the results clearly demonstrate that visual elucidations of basic image-schematic content not only do enhance performance on the more concrete instances of EPVs, but also significantly improve inferences of related abstract meanings of such verbs.

Isolated dictionary-like definitions and/or examples of EPVs strung together in a list, such as the ones used in control group classroom activities in this study, create more struggle than service in helping learners' smooth transition from concrete to abstract meaning (see Tyler \& Evans, 2005 For similar views). In practice, dictionaries tend to coax learners into believing that multiple, discretely numbered definitions of an EPV present unrelated and distinct senses of an accidental homonymy!

For a thorough work on EPVs, Condon (2008) constitutes an interesting piece of research. She reports findings of a large-scale study where large groups of EFL learners are presented with instruction of EPVs using different CLmotivations. The conclusions she reaches support the general idea that CL-informed explicit instruction of underlying concepts in EPVs help retention and transfer of knowledge to other similar EPVs instantiating the same concepts. However, her instructions comprise detailed verbal explanations of CL motivations behind phrasal verbs, instructions which clearly increase the learning load on the part of the student (see Baddeley, 1997, for memory processing and constraints). As she later contends, even the simplified statements she used in her instructions might have been "relatively abstract and hard to visualize," and that "such spare generalizations may not always be pedagogically appropriate, particularly in relation to relatively abstract phrasal verbs" (Condon 2008, p. 153).

\footnotetext{
${ }^{8}$ We strictly controlled for our participants' subsequent learning or course participation in the period of time allowed between the two posttests.
} 


\section{CONCLUSION AND SugGESTIONS FOR FuRTHER RESEARCH}

The primacy and pervasiveness of tangible visual-spatial experience and conceptual/linguistic abstraction is an indispensible part of linguistic thinking and expression that a theory of language must account for (Slobin, 1996). Perhaps, it is fair to claim that CL is currently the most relevant and informative theory assuming a close-knit tie between image-schematic representation, abstract conceptualization, and linguistic expression (Langacker, 1991; Talmy, 2000, 2008; Tyler \& Evans, 2001). Insights from CL theory and research, when properly applied for pedagogical purposes, can contribute to fostering even more creativity and efficiency in language pedagogy (De Knop et al., 2010).

A word of caution seems appropriate here: the key basis for the creation and development of image schemas in the mind of the native speaker is life-long, enduring presence in his/her socioculturally rich, native language environment (Gibbs \& O'Brien, 1990). As Mandler (1992; 2004) points out, humans create mental image schemas and their relevant abstract conceptual patterns through a process of reanalysis of perceptual experience arising from recurring experiential encounters with the tangible events in the surrounding socio-cultural context. It is a serious mistake to assume that this genuine, enduring process can ever be replaced by a few sessions of experience and activity on the part of the foreign language learner in an artificial classroom environment. Nevertheless, the aim of this research is to demonstrate, perhaps for the first time, that such a natural process of sensory experience could be mimicked, however minimally and insufficiently, to enhance learners' awareness and raise their consciousness toward bits and pieces of such experience as to render it slightly more meaningful to them. Further, as argued before, the long-term, mnemonic aspects of this experience should not be neglected (Boers et al., 2008).

In our design of test material, we used meaningful storylines to further create genuine contextualized and communicative instance of EPVs in use. We also paralleled the concrete and abstract uses of the EPVs under study in our test material to enhance learner awareness and recognition of relations between these verbs. These ideas can also be helpful to test designers and textbook writers in their construction of test and practice material. As Tyler \& Evans (2005) maintains, such tasks can create a firm ground for learners from which to infer the meanings of extended abstract uses of linguistic expressions they encounter in various contexts of use. Grouping of visual elucidations into concrete/abstract sequences accompanied by meaningful, contextualized sentences can further pave the way for learners to effectively comprehend and retain essential graphic information.

One beneficial line of research is to observe if learners, in an extended course of instruction expanding over several years, could possibly become capable of "independently" arriving at connections and extensions of concrete to abstract senses in EPVs over time. Studies can also be designed to check to what extent learners recognize and appreciate the effective uses of pictorial elucidation tasks and/or possibly what other advantages could be gained from this kind of approach to teaching/learning.

The tasks in this study represented creative yet intuitive ways of designing classroom activities to enhance learning and teaching EPVs. Further research can be carried out creating and adopting more systematic and principled ways of designing similar tasks for classroom instruction and tests. In practical terms, due to limitations imposed by the institute, we were obliged to include male-only students of English with a Persian mother tongue background ${ }^{9}$. Further research can explore possibilities of research with both sexes and members of other L1 backgrounds in order to be able to interpret the data and apply the findings with greater certainty to a wider population. Last but not least, this study was mainly product-oriented in that we only asked for and used students' responses to questions on end-of-term written tests. Other research studies could take the initiative further and conduct more systematic analyses of students' responses from a process-oriented perspective using ongoing classroom data.

\section{APPENDIX}

A. Two sample "picture-cued tasks" \& their order of presentation in the experimental group (first, the more literal one(s) on the left and then, the more figurative one(s) on the right):

\section{1) Hold on to:}
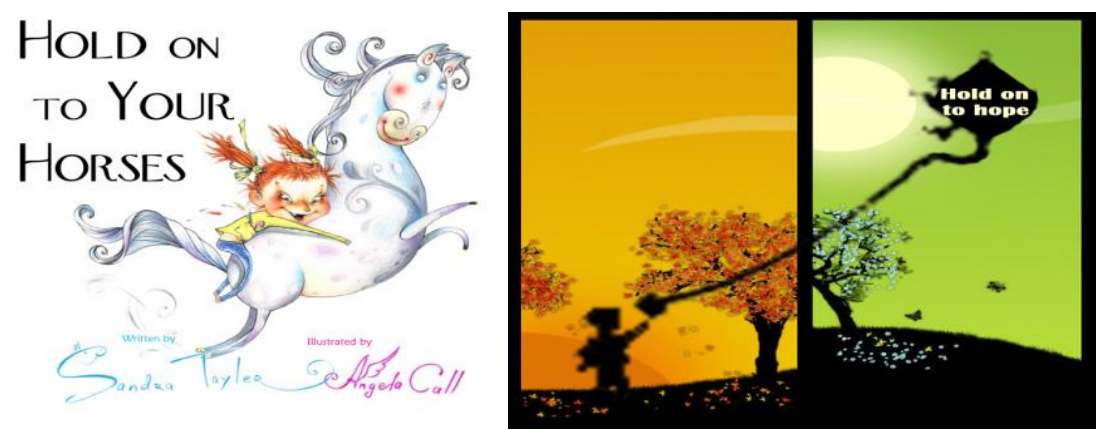

\footnotetext{
${ }^{9}$ Note that according to general educational laws in Iran, schools and institutes cannot offer coeducational courses.
} 


\section{2) Sign in:}

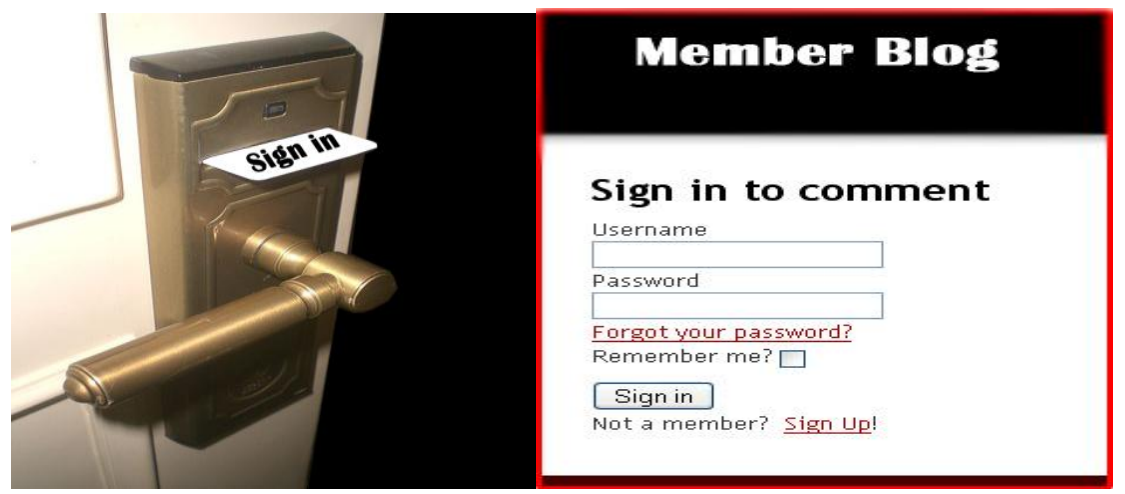

B. Sample classroom learner descriptions for picture task (a) above:

1) More concrete picture on the left: "I can see a small girl. She is on the horse. She is holding her hands...tightly on the sides. The horse is maybe running toward a...garden [he looks for a garden in the picture and adds,] I suppose! The girl is trying to hold the horse's...'neck' not to fall down. Yes, she's holding...fast to the horse. Um, yeah, she's holding... on...to the horse."

2) More abstract picture on the right: "Um, as I understand it, this means... [taking a passing glance at the 'girl \& horse ' picture on the left like the girl and the horse! I mean, ...like the girl who's holding her hands onto the horse to go to garden, we should hold fast to hope...which like the horse is good for us...because it takes us to ....a good situation. We hold...on to...hope to go... until a warm season like the girl who's holding on to the horse to go...home or to win, um, maybe?! Yes?"

C. We sometimes provided more picture drawings to smooth experimental participants' transition from concrete to abstract meaning (e.g., for "1.a" above):
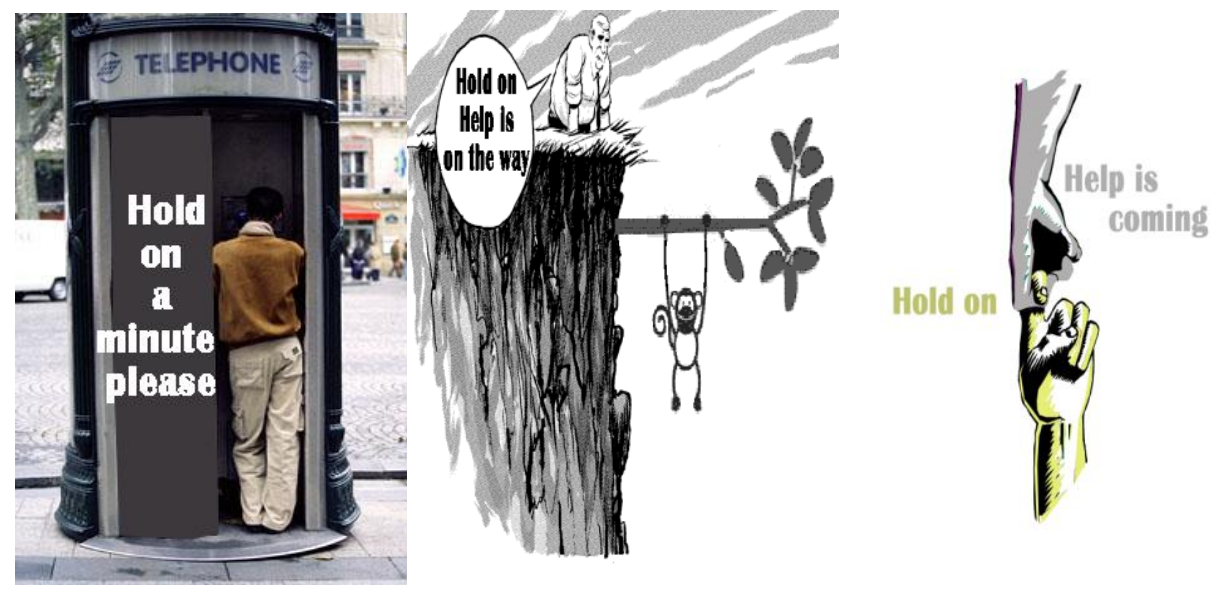

\section{ACKNOWLEDGEMENT}

We are very grateful to Hassan M. Farsani, the cartoonist/graphic artist, who took the trouble of creating the majority of the picture drawings for each classroom session in our courses and gave us kind permission to publish some of his works in the appendix. We also thank Sandra Taylor and Angella Call for generously granting us permission to publish their artwork Hold on to Your Horses" as part of this article (http://www.holdontoyourhorses.com/).

\section{REFERENCES}

[1] Allsop, J. (1990). Test your phrasal verbs. Edinburgh: Pearson ESL.

[2] Azzaro, G. (1988). English phrasal verbs: Identifying the learning problems. Bangor: University of Wales.

[3] Baddeley, A. (1997). Human memory: Theory and practice. Hove: Psychology Press Ltd.

[4] Boers, F. (2000). Metaphor awareness and vocabulary retention. Applied Linguistics 21: 553-571.

[5] Boers, F. (2011). Cognitive semantic ways of teaching figurative phrases: An assessment. In F. Gonzálvez García, M. S. Peña Cervel \& L. Pérez Hernández (eds.), Metaphor and metonymy revisited beyond the contemporary theory of metaphor: Recent developments and applications, 227-261. Berlin/New York: Mouton de Gruyter. 
[6] Boers, F. \& S. Lindstromberg (eds.) (2008). Cognitive linguistic approaches to teaching vocabulary and phraseology. Berlin/New York: Mouton de Gruyter.

[7] Boers, F., S. Lindstromberg, J. Littlemore, H. Stengers \& J. Eyckmans (2008). Variables in the mnemonic effectiveness of pictorial elucidation. In F. Boers \& S. Lindstromberg (eds.), 189-216.

[8] Bolinger, D. (1971). The phrasal verb in English. Cambridge, MA: Harvard University Press.

[9] Breen, M. (1987). Learner contribution to task design. In C. Candlin \& D. Murphy (eds.), Language learning tasks, $23-46$. London: Prentice Hall.

[10] Brown, H. D. (2010). Language assessment: Principles and classroom practices (2 ${ }^{\text {nd }}$ ed.). Edinburgh: Pearson ESL.

[11] Burke, D. (2002). The slangman guide to street speak 3. CA: Slangman Publishing.

[12] Cambridge phrasal verbs dictionary. (2006). Cambridge: Cambridge University Press.

[13] Collis, H. (2007). 101 American English idioms (2 $2^{\text {nd }}$ ed.). London: McGraw-Hill.

[14] Collis, H. \& J. Kohl (1999). 101 American customs. London: McGraw-Hill.

[15] Condon, N. (2002). A cognitive approach to phrasal verbs: How useful is it? Paper presented at IVACS Conference, June 2002, University of Limerick, Ireland.

[16] Condon, N. (2008). How cognitive linguistic motivations influence the learning of phrasal verbs. In Boers, F. \& Lindstromberg, S. (eds.), 133-158.

[17] Csábi, S. (2004). A cognitive linguistic view of polysemy in English and its implications for teaching. In M. Achard \& S. Niemeier (eds.), Cognitive linguistics, second language acquisition, and foreign language teaching, 233-256. Berlin/New York: Mouton de Gruyter.

[18] Dagut, M. B. \& B. Laufer (1985). Avoidance of phrasal verbs by Hebrew-speaking learners of English - a case for contrastive analysis. Studies in Second Language Acquisition 7: 73-79.

[19] De Bot, K. \& B. Weltens (1995). Foreign language attrition. Annual Review of Applied Linguistics, 15, 151-164.

[20] De Knop, S., F. Boers \& A. De Rycker (eds.) (2010). Fostering language teaching efficiency through cognitive linguistics. Berlin/New York: Mouton de Gruyter.

[21] Dirven, R. (2001). English phrasal verbs: Theory and didactic application, in: M. Pütz \& S. Niemeier (eds.), Applied cognitive linguistics, vol. II: Language pedagogy, 3-28. Berlin/New York: Mouton de Gruyter.

[22] Ellis, N. C. \& N. Laporte (1997). Contexts of acquisition: Effects of formal instruction and naturalistic exposure on second language acquisition. In A. M. DeGroot \& J. F. Kroll (eds.), Tutorials in bilingualism: Psycholinguistic perspectives, 53-83. Mahwah NJ: Lawrence Erlbaum Associates.

[23] Fauconnier, G. \& M. Turner (2002). The way we think: Conceptual blending and the mind's hidden complexities. New York: Basic Books.

[24] Geeraerts, D. \& H. Cuyckens (2007). Introducing cognitive linguistics. In D. Geeraerts \& H. Cuyckens (eds.), Oxford handbook of cognitive linguistics, 3-21. Oxford: Oxford University Press.

[25] Gibbs, R. \& J. O’Brien (1990). Idioms and mental imagery: The metaphorical motivation for idiomatic meaning. Cognition, 36, 35-64.

[26] Gibbs, R., J. Bogdonovich, J. Sykes \& D. Barr (1997). Metaphor in idiom comprehension. Journal of Memory and Language, $37,141-154$.

[27] Gibbs, R., L. K. Strom \& M. J. Spivey-Knowlton (1997). Conceptual metaphors in mental imagery for proverbs. Journal of Mental Imagery, 21(3-4), 83-109.

[28] Hart, C.W. (2009). The ultimate phrasal verb book ( $2^{\text {nd }}$ ed.). New York: Barron's.

[29] Hughes, A. (1989). Testing for language teachers. Cambridge: Cambridge University Press.

[30] Johnson, M. (1987). The body in the mind: The bodily basis of meaning, imagination and reason. Chicago: Chicago University Press.

[31] Kurtyka, A. (2001). Teaching English phrasal verbs: A cognitive approach. In M. Pütz, S. Niemeier \& R. Dirven (eds.), Applied cognitive linguistics, vol. II: Language pedagogy, 29-54. Berlin/New York: Mouton de Gruyter.

[32] Lakoff, G. (1987). Women, fire, and dangerous things. Chicago: University of Chicago Press.

[33] Lakoff, G. \& M. Johnson (1980). Metaphors we live by. Chicago: University of Chicago Press.

[34] Lakoff, G. \& M. Johnson (1999). Philosophy in the flesh: The embodied mind and its challenge to western thought. Chicago: Basic Books.

[35] Langacker, R. (1991). Concept, image and symbol: The cognitive basis of grammar. Berlin: Mouton de Gruyter.

[36] Littlewood, W. (2004). The task-based approach: Some questions and suggestions. ELT Journal, 58, 4: 319-326.

[37] Long, M. H. (1985). A Role for instruction in second language acquisition. In K. Hyltenstam, \& M. Pienemann (eds.), Modeling and assessing second language acquisition. Clevedon Avon: Multilingual Matters.

[38] Longman phrasal verbs dictionary. (2000). London: Longman.

[39] Longman dictionary of contemporary English. (2009). London: Pearson Longman.

[40] Mandler, J. (1992). How to build a baby II. Conceptual primitives. Psychological Review 99, 567-604.

[41] Mandler, J. (2004). The foundations of mind: Origins of conceptual thought. Oxford: Oxford University Press.

[42] Madsen, H. S. (1983). Techniques in testing. Oxford: Oxford University Press.

[43] McCarthy, M. \& F. O'Dell (2007). English phrasal verbs in use: Advanced. Cambridge: Cambridge University Press.

[44] McGlone, M. (1996). Conceptual metaphor and figurative language understanding: Food for thought? Journal of Memory and Language, 35, 544-565.

[45] McIntosh, C. (ed.) (2006). Oxford phrasal verbs dictionary for learners of English. Oxford: Oxford University Press.

[46] Nayak, N. \& R. Gibbs (1990). Conceptual knowledge in the interpretation of idioms. Journal of Experimental Psychology: General, 119, 315-330.

[47] Norris, J. \& L. Ortega (2000). Effectiveness of L2 instruction: A research synthesis and quantitative meta-analysis. Language Learning, 50, 417-528.

[48] Nunan, D. (1999). Second language teaching and learning. Boston: Heinle \& Heinle. 
[49] Oxford University Press. (2005). Oxford placement test. http://www.lang.ox.ac.uk/courses/tst_english_placement.html. (Accessed 5/9/2005).

[50] Paivio, A. (1986). Mental representations: A dual coding approach. New York: Oxford University Press.

[51] Richards, J.C, J. Hull \& S. Proctor (2005). Interchange ( ${ }^{\text {rd }}$ ed.). Cambridge; Cambridge University Press.

[52] Richards, J. C. \& T. S. Rodgers (2001). Approaches and methods in language teaching ( $2^{\text {nd }}$ ed.). Cambridge; Cambridge University Press.

[53] Robinson, P. \& N. C. Ellis (2008). Cognitive linguistics, second language acquisition and L2 instruction-issues for research. In Robinson, P. \& N. C. Ellis (eds.), Handbook of cognitive linguistics and second language acquisition, 489-545. London: Routledge.

[54] Rohrer, T. (2007). Embodiment \& experientialism. In D. Geeraerts \& H. Cuyckens (eds.), Oxford handbook of cognitive linguistics, 25-47. Oxford: Oxford University Press.

[55] Rosch, E. (1977). Human categorization. In N. Warren (ed.), Studies in cross-cultural psychology, Vol. I, 3-49. London: Academic Press.

[56] Rudzka-Ostyn, B. (2003). Word power: Phrasal verbs and compounds. Berlin/New York: Mouton de Gruyter.

[57] Samuda, V. \& M. Bygate (2008). Tasks in second language learning. Basingstoke: Palgrave Macmillan.

[58] Schmid, M. S. (2006). Second language attrition. In K. Brown (ed.), The encyclopedia of language and linguistics, Vol. 11, 7481. Amsterdam: Elsevier.

[59] Side, R. (1990). Phrasal verbs: Sorting them out. ELT Journal 44: 144-152.

[60] Skandera, P. (ed.) (2007). Phraseology and culture in English. Berlin/New York: Mouton de Gruyter.

[61] Skehan, P. (1998). A cognitive approach to language learning. Oxford; Oxford University Press.

[62] Slobin, D. I. (1996). From "thought and language" to "thinking for speaking." In J. Gumperz \& S. Levinson (eds.), Rethinking linguistic relativity: Studies in the social and cultural foundations of language, vol. 17, 70-96. Cambridge: Cambridge University Press.

[63] Spivey-Knowlton, M. J., M. Tanenhaus, K. Eberhard \& J. Sedivy (1998). Integration of visuospatial and linguistic information: language comprehension in real time and real space. In P. Oliver, \& K. P. Gapp (eds.), Representation and processing of spatial expressions, 201-214. Mahwah, N.J.: Lawrence Erlbaum Associates.

[64] Talmy, L. (2000). Towards a cognitive semantics (2 vols). Cambridge, MA: MIT Press.

[65] Talmy, L. (2008). Aspects of attention on language. In P. Robinson \& N. C. Ellis (eds.), 27-38.

[66] Tomasello, M. (2003). Constructing a language: A usage-based theory of language acquisition. Cambridge, MA: Harvard University Press.

[67] Tyler, A. \& V. Evans (2001). The relation between experience, conceptual structure and meaning: Non-temporal uses of tense and language gteaching. In M. Pütz, S. Niemeier \& R. Dirven (eds.), Applied cognitive linguistics I: Theory and language acquisition, 63-108. Berlin: Mouton de Gruyter.

[68] Tyler, A. \& V. Evans (2005). Applying cognitive linguistics to pedagogical grammar: The English prepositions of verticality. Revista Brasileira de Linguistica Aplicada, 5(2), 11-42.

[69] Vahid Dastjerdi, H. \& M. R. Talebinezhad (2002). Conceptual mappings, perception and production of L2 metaphorical expressions. International Journal of Humanities, 9(3), 47-61.

[70] Willis, D. \& J. Willis (2007). Doing task-based teaching. Oxford: Oxford University Press.

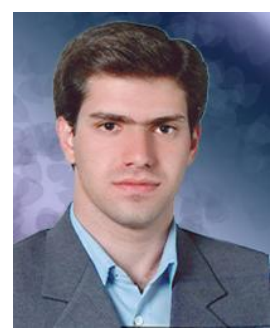

Hussein Muhammadi Farsani is currently PhD candidate in applied linguistics at the University of Isfahan, Isfahan, Iran. He received his Bachelor's degree in English language \& literature from the University of Kashan in 2003 and his Master's degree in TEFL (teaching English as a foreign language) from the University of Isfahan in 2005.

He has more than ten years of experience in Teaching English as a Foreign Language and more than three years of experience in teaching courses in Linguistics and Second/Foreign Language Pedagogy at various state and open universities. He is currently working as a Researcher at the University of Isfahan as well as a Teacher Trainer at the Language Center for Isfahan Medical School, Isfahan, Iran. His most recent publication is: Farsani, H. M., M. Tavakoli \& A. Moinzadeh (forthcoming). The Effect of Task-Based Instruction on the Acquisition and Use of English Existential Constructions by Iranian EFL Learners. Innovation in Language Learning and Teaching, http://www.tandfonline.com/doi/abs/10.1080/17501229.2011.604419 (accessed 17/12/2011).

Ahmad Moinzadeh is currently assistant professor of linguistics at the Department of English, University of Isfahan, Isfahan, Iran He received his B.A. in English language and literature from the University of Isfahan in 1983 and his M.A. in TEFL in 1986 from Ferdowsi University, Mashhad, Iran. He received his PhD in linguistics in 2001 from the University of Ottawa, Canada. He teaches courses in Linguistics and Second Language Acquisition at the University of Isfahan.

Mansoor Tavakoli is assistant professor of English language teaching and testing at the Department of English, University of Isfahan, Isfahan, Iran. He received his B.A. in English language teaching from the University of Isfahan in 1990 and an M.A. in the same field in 1994 from the University of Tarbiat-Modarres, Tehran, Iran. He received his PhD in applied linguistics in 2004 from the University of Isfahan, Iran. He currently teaches courses in Second/Foreign Language Testing and Research at the University of Isfahan. 